\title{
Sleep quality and its impacts on quality of life among military personnel in remote frontier areas and extreme cold environments
}

\author{
Zonghua Wang ${ }^{1}$, Beijing Chen ${ }^{1}$, Wei Li ${ }^{1}$, Fei Xie ${ }^{1}$, Alice Yuen Loke ${ }^{2^{* \dagger}}$ and Qin Shu ${ }^{1{ }^{* \dagger}}$ (D
}

\begin{abstract}
Background: Poor sleep quality negatively affects the readiness of military operations and is also associated with the development of mental health disorders and decreased quality of life. The purpose of this study was to investigate the sleep quality of military personnel from remote boundaries of China and its relationship with coping strategies, anxiety, and health-related quality of life (HRQoL).

Methods: A cross-sectional survey was performed among military officers and soldiers from a frontier defence department and an extreme cold environment. The participants were surveyed using the Pittsburgh Sleep Quality Index (PSQI), Trait Coping Style Questionnaire (TCSQ), Self-rating Anxiety Scale (SAS), and Short Form Health Survey (SF-36).

Results: A total of 489 military officers and soldiers were included. The participants had a mean age of 22.29 years. The median overall PSQI score was 7.0 (IQR, 4.0 9.0), with 40.9\% (200/489) of the subjects reporting poor sleep quality. The difficulties with sleep were mainly related to daytime dysfunction due to disrupted sleep, sleep latency, and subjective sleep quality. The median score of the SF-36 physical component was 83.5 (IQR, $73.0 \sim 90.5)$, and the median score of the mental component was 74.1 (IQR, 60.4 85.1). Significant correlations were found between the PSQI and SF-36 $(r=-0.435, P<0.01)$. Anxiety symptoms, marital status, educational background, and global PSQI score were demonstrated as predictors of a low SF-36 physical component by multiple regression analysis $(F=$ 17.06, $P<0.001, R^{2}=0.117$ ).

Conclusions: Sleep difficulty is a prevalent and underestimated problem in the military that negatively influences HRQOL, especially in physical and social functioning. Evaluation of and education on pain were recommended because of body pain and its negative impacts on sleep quality, coping strategies, anxious emotions and HRQoL.
\end{abstract}

Keywords: Sleep, Military, PSQI, HRQoL

\footnotetext{
*Correspondence: alice.yuen.loke@polyu.edu.hk; qinshu_amu@163.com

${ }^{+}$Alice Yuen Loke and Qin Shu contributed equally to this work.

${ }^{2}$ School of Nursing, the Hong Kong Polytechnic University, Hung Hum, Kowloon, Hong Kong, China

${ }^{1}$ School of Nursing, Army Medical University, Chongqing 400038, China
}

(c) The Author(s). 2020 Open Access This article is licensed under a Creative Commons Attribution 4.0 International License, which permits use, sharing, adaptation, distribution and reproduction in any medium or format, as long as you give appropriate credit to the original author(s) and the source, provide a link to the Creative Commons licence, and indicate if changes were made. The images or other third party material in this article are included in the article's Creative Commons licence, unless indicated otherwise in a credit line to the material. If material is not included in the article's Creative Commons licence and your intended use is not permitted by statutory regulation or exceeds the permitted use, you will need to obtain permission directly from the copyright holder. To view a copy of this licence, visit http://creativecommons.org/licenses/by/4.0/. The Creative Commons Public Domain Dedication waiver (http://creativecommons.org/publicdomain/zero/1.0/) applies to the data made available in this article, unless otherwise stated in a credit line to the data. 


\section{Background}

Sleep loss and sleep disruption are prevalent among military service members. Military operations are stressful, unexpected, urgent, and often take place in austere environments, predisposing soldiers to insufficient and poor quality sleep. A study reported a dramatic increase in clinically significant sleep disorders among officers who were involved in the combat operation of Operation Iraqi Freedom [1]. A study in the United States reported that nearly half of military personnel were screened as positive for disturbed sleep. However, inadequate and poor quality sleep is regarded as 'normal' and 'unavoidable' among military personnel because of the nature of military operations and special missions that frequently require shift work, long-term field training, and rapid deployment across multiple time zones [2]. Sleep disorders and their negative impacts are commonly underestimated because in the military, missions are always the priority, and there is no chance to consider sleep.

The promotion of healthy sleep is critical to the physical and behavioural health of individual military members as well as to the functioning of the entire unit [3]. Emerging evidence suggests that sleep difficulties and/or sleep disruptions have been associated with the development of mental health disorders, including depression, anxiety, post-traumatic stress disorder (PTSD), and eventually, a decrease in health-related quality of life (HRQoL) [4-9]. In particular, poor sleep quality can negatively affect military operational readiness, safety and effectiveness through reduced cognitive performance, such as impaired attention, concentration, responsiveness, judgement, and critical thinking [10, 11].

However, very few studies have been conducted on sleep quality and its impacts on HRQoL among the Chinese military population, particularly among those who served at the country borders and in extreme cold environments $[12,13]$. Military personnel who serve at borders, which are challenged by both hostile environments in remote areas with disputes over border and religious conflicts, are vulnerable to poor sleep quality and HRQoL. This study attempted (1) to investigate the current status of sleep quality among military service members at remote boundaries and in extreme cold environments in China; (2) to explore the association between poor sleep quality and HRQoL; and (3) to identify factors that could affect sleep quality and HRQoL.

\section{Methods}

\section{Study design and participants}

This was a cross-sectional study. Data on sleep quality, coping strategies, anxiety level, and HRQoL were collected with self-administered questionnaires. Five hundred military officers and soldiers were recruited from a frontier defence department in February 2018. The frontier defence department is located in a city in northwestern China. The city name literally means 'new frontier' or 'new territory' in Chinese language, and the city occupies roughly one-sixth of China's total area. Featuring vast, inhospitable desert and massive snow-capped mountains, the city is known by geographers as 'the dead heart of Asia' and China's 'Wild West'. It has a $5600 \mathrm{~km}$ boundary and is challenged by border disputes and religious conflicts. The temperature during winter was 20 degrees below zero on average. Military personnel were considered eligible for inclusion if they were (1) aged 18 to 60 years, (2) able to read, write and speak Mandarin, (3) willing to participate in the study, and (4) able to give informed consent.

\section{Questionnaire}

The questionnaire consisted of five parts: demographics, the Pittsburgh Sleep Quality Index [14], the Self-rating Anxiety Scale [15], the Trait Coping Style QuestionnaireChinese version [16], and the Chinese version of the Medical Outcomes Study Short Form-36 [17].

Part 1 was to solicit demographic information about the participants, including age, sex, marital status, education level, and years of service in the military.

Part 2 consisted of the Pittsburgh Sleep Quality Index (PSQI) [14], which was used to assess participant sleep quality and disturbances over a one-month period. The PSQI is composed of 19 items in seven components: subjective sleep quality (SQ), sleep latency (SL), sleep duration (SD), habitual sleep efficiency (SE), sleep disturbances (SB), the use of sleep medication (SM), and daytime dysfunction due to disrupted sleep (DD) [18]. The items were rated on a 3-point Likert scale with ' 0 ' indicating no difficulty and ' 3 ' indicating severe difficulty. For each item, scores $\geq 2$ indicated poor sleep quality. The overall PSQI score ranges from 0 to 21, with higher scores indicating poorer sleep quality and more sleep disturbances. The Cronbach's $\alpha$ coefficient of the Chinese PSQI was $0.71 \sim 0.83[19,20]$, indicating acceptable levels of reliability. In our participants, the Cronbach's $\alpha$ value was 0.78 . The PSQI is a self-reported questionnaire that distinguishes 'a good sleeper' as having a PSQI global score $\leq 7$ and 'a poor sleeper' as having a PSQI score $\geq 8$ [21].

Part 3 was the Self-rating Anxiety Scale (SAS) [15], which was used to explore military officers' anxietyrelated complaints. The SAS is a 20-item 4-point Likert scale assessing both affective and somatic symptoms, with $1=$ a little of the time and $4=$ most of the time. The raw scores, which range from 20 to 80 , are converted to standard scores by dividing the sum of the raw scores by 80 and multiplying by $100[22,23]$. The higher the overall score, the more frequently anxiety symptoms are experienced. The internal consistency coefficient of 
the Chinese version of the SAS was 0.84 [24]. In our subjects, the Cronbach's $\alpha$ score was 0.77 . SAS standard scores greater than 50 indicate clinically significant anxiety $[25,26]$.

Part 4 was the Trait Coping Style QuestionnaireChinese version (TCSQ) [16], which was used to assess the coping strategies of the participants. The TCSQ was developed based on a review of the existing literature and a content analysis of coping strategies and adopted for use in the Chinese population [27]. The scale consists of 20 items rated on a 5point Likert scale and evaluates two components: positive coping style (10 items) and negative coping style (10 items). The Cronbach's $\alpha$ coefficients of the positive and negative coping subscales were 0.79 and 0.78 , respectively [28]. In our sample, the internal consistency values of the positive and negative subscales were 0.72 and 0.80 , respectively.

Part 5 was the Chinese version of the Medical Outcomes Study Short Form-36 (MOS-SF-36) [17], which was used to assess HRQoL. The MOS-SF-36 includes 36 items that correspond to eight domains grouped into two components: the physical component summary (PCS) includes general health (GH); role limitations due to physical health (role-physical, RP); bodily pain (BP); and physical functioning (PF). The mental component summary (MCS) includes mental health $(\mathrm{MH}$, also known as emotional well-being); vitality (VT, also known as energy/fatigue); role limitations due to emotional problems (role-emotion, RE); and social functioning (SF). Each item of the SF-36 is assessed using points scored on a Likert scale [29]. The raw scores of each of the eight domains are calculated by summing the scores of all items and then a transformed score is calculated as follows: transformed score $=$ (actual raw score - lowest possible raw score)/(possible max raw score) $* 100$. The PCS and MCS scores range from 0 to 100 points, with higher scores indicative of better HRQoL. The Cronbach's $\alpha$ score of each domain ranges from 0.39 to 0.88 [30]. In our participants, the Cronbach's $\alpha$ score of each domain ranged from 0.51 to 0.89 , with a Cronbach's $\alpha$ coefficient for the overall scale of 0.82 .

\section{Data collection}

The data were collected after a seminar, and the questionnaires were administered anonymously. This study was conducted in accordance with the ethical principles of the Declaration of Helsinki.

\section{Ethical considerations}

Ethical approval was obtained from the human ethics committee of the Army Medical University.

\section{Data analysis}

Statistical Package for the Social Sciences 21.0 (SPSS Inc., Chicago, IL) were adopted to perform the data analysis. The descriptive statistics (median, interquartile range [IQR], number and percentage) were calculated. A normal distribution was not observed in our variables with the Kolmogorov-Smirnov test. The Mann-Whitney $\mathrm{U}$ test or Kruskal-Wallis test was used to compare two or more variables for the PSQI and HRQoL.

Correlations between variables were investigated with Spearman's correlation coefficient. According to Ratner [31], a coefficient below 0.3 represents a weak correlation, a coefficient between 0.3 and 0.7 means a moderate correlation, and a coefficient higher than 0.7 corresponds to a high correlation.

Multivariate linear regression analysis (stepwise regression) was performed to determine the impacts of sleep quality on HRQoL. A $p$-value less than 0.05 was considered statistically significant.

\section{Results \\ Sample characteristics}

Five hundred military officers and soldiers were randomly recruited from a military unit in February 2018. A total of 498 questionnaires were returned, and nine of them were excluded because of $50 \%$ or more items missing data. As a result, only 489 questionnaires were included in the final analysis.

The 489 participants were 22.3 years old (ranging from 18 to 38$)$ on average. The majority of them were males $(n=478,97.8 \%)$ and enlisted military personnel $(n=417$, 85.3\%). Among them, 11 (2.2\%) were health care workers, 38 (7.8\%) were administrative workers, and 440 $(90.0 \%)$ were soldiers who received training in snow hunting in the Gobi Desert and in counterterrorism combat in a depopulated zone.

The participants had served in the military for an average of 35.3 months, ranging from 4 to 217 months. Approximately two-thirds $(n=317)$ had served for less than 3 years, one-fifth $(n=99)$ had served for 3 to 6 years, and only 41 of them (9\%) had served for 6 to 9 years.

\section{Anxiety}

The anxiety scores of our study participants ranged from the lowest score of 25.0 to the highest score of 81.3, with a median score of 40.0 (IQR, $35.6 \sim 45.0$ ). The participants with a habit of drinking showed a higher level of anxiety than those without a habit of drinking $(P=$ 0.046) (Table 1). The participants with a high level of anxiety (SAS score $>50$ ) had worse HRQoL in terms of bodily pain $(P<0.01)$ and physical functioning $(P=$ 0.010) (Table 3). 
Table 1 Comparisons on the scores of PSQI, anxiety and coping styles by different individual characteristics

\begin{tabular}{|c|c|c|c|c|c|c|c|c|c|c|}
\hline Variables & n (\%) & $\begin{array}{l}\text { Anxiety } \\
\text { median(IQR) }\end{array}$ & global PSQI & SQ & SD & SE & SB & $\mathrm{DD}$ & $P C$ & $\mathrm{NC}$ \\
\hline \multicolumn{11}{|l|}{ Age (years) } \\
\hline$\leq 20$ & 168(34.3) & $40(36.3-46.3)$ & $6.9(4-9.8)$ & $1(1-2)$ & $1(0-1)$ & $0(0-1)$ & $1(0.9-1)$ & $2(1-3)$ & $35(31-39)$ & $26(18.3-31)$ \\
\hline $21 \sim 30$ & $306(62.6)$ & $40(35-43.8)$ & $7(4-9)$ & $1(1-2)$ & $1(0-1)$ & $0(0-1)$ & $1(1-2)$ & $2(1-3)$ & $35(31-39)$ & $25(19-30)$ \\
\hline$>30$ & $15(3.1)$ & $40(35-48.8)$ & $7(5-10)$ & $1(1-2)$ & $1(1-2)$ & $1(0-1)$ & $1(1-2)$ & $2(1-2)$ & $34(30.8-36.3)$ & $26(23-31)$ \\
\hline$P$ value & & 0.544 & 0.832 & 0.966 & 0.002 & $0.047^{*}$ & 0.713 & 0.611 & 0.282 & 0.819 \\
\hline \multicolumn{11}{|l|}{ Gender } \\
\hline Male & 478(97.8) & $40(36.3-45)$ & $7(4-9)$ & $1(1-2)$ & $1(0-1)$ & $0(0-1)$ & $1(1-1)$ & $2(1-3)$ & $35(31-39)$ & 25(19-30) \\
\hline Female & $11(2.2)$ & $40(32.5-48.8)$ & $8(6-10)$ & $2(1-2)$ & $1(1-1)$ & $0(0-0)$ & $1(1-2)$ & $2(2-3)$ & $37(33-39)$ & $28(22-31)$ \\
\hline$P$ value & & 0.844 & 0.294 & 0.386 & 0.391 & 0.329 & 0.093 & 0.226 & 0.394 & 0.355 \\
\hline \multicolumn{11}{|l|}{ Marriage } \\
\hline Unmarried & 459(93.9) & $40(35-45)$ & $7(4-9)$ & $1(1-2)$ & $0(0-1)$ & $0(0-1)$ & $1(1-1)$ & $2(1-3)$ & $35(31-39)$ & $25(19-30)$ \\
\hline Married & $30(6.1)$ & $38.8(35.9-49.1)$ & $7(5-9)$ & $1(1-2)$ & $1(1-2)$ & $0(0-1)$ & $1(1-1)$ & $2(1-3)$ & $34(30-37)$ & $26.5(19.8-31.3)$ \\
\hline$P$ value & & 0.909 & 0.559 & 0.992 & $0.005^{* *}$ & 0.468 & 0.239 & 0.320 & 0.202 & 0.414 \\
\hline \multicolumn{11}{|l|}{ Education } \\
\hline Primary & $24(4.9)$ & $42.5(40-54.4)$ & $6.5(4.3-10)$ & $1(0.3-2)$ & $1(1-1.8)$ & $0(0-1)$ & $1(1-1)$ & $2(1-2.8)$ & $33(30-35)$ & $26(20.3-31.5)$ \\
\hline Middle & $243(49.7)$ & $40(35-45)$ & $6(3-9)$ & $1(1-2)$ & $1(0-1)$ & $0(0-1)$ & $1(0-1)$ & $1(0-2)$ & $35(31-39)$ & $25(18-30)$ \\
\hline College/University & 147(30.1) & $40(36.3-46.3)$ & $7(4-10)$ & $1(1-2)$ & $1(0-1)$ & $0(0-1)$ & $1(1-1)$ & $2(1-3)$ & $35(31-39)$ & $26(19-31)$ \\
\hline Postgraduates & 75(15.3) & $38.8(35-43.8)$ & $7(5-8)$ & $1(1-2)$ & $1(1-2)$ & $0(0-1)$ & $1(1-1)$ & $2(1-3)$ & $36(32-40)$ & $26(19-30)$ \\
\hline$P$ value & & 0.107 & 0.055 & 0.244 & $0.000^{* *}$ & 0.997 & $0.000^{* *}$ & $0.009^{* *}$ & 0.210 & 0.552 \\
\hline \multicolumn{11}{|l|}{ Current Drinker } \\
\hline Yes & $36(54.0)$ & $41.9(38.8-54.4)$ & $8.5(6-12)$ & $1(1-2)$ & $1(1-1)$ & $0(0-1)$ & $1(1-1)$ & $2(1-3)$ & $32.5(27.8-39)$ & $26(23.3-32.8)$ \\
\hline No & $453(46.0)$ & $40(35-45)$ & $7(4-9)$ & $1(1-2)$ & $1(0-1)$ & $0(0-1)$ & $1(1-1)$ & $2(1-3)$ & $35(32-39)$ & $25(18-30)$ \\
\hline$P$ value & & $0.004^{* *}$ & $0.003^{* *}$ & 0.053 & 0.251 & 0.441 & $0.006^{* *}$ & 0.081 & $0.046^{*}$ & $0.031^{*}$ \\
\hline \multicolumn{11}{|l|}{ Current Smoker } \\
\hline Yes & $264(54.0)$ & $40(36.3-45)$ & $7(5-9)$ & $1(1-2)$ & $1(0.3-1)$ & $0(0-1)$ & $1(1-1)$ & $2(1-3)$ & $35(31.3-39)$ & $26(19-31)$ \\
\hline No & $225(46.0)$ & $40(35-45)$ & $6(3.5-9)$ & $1(1-2)$ & $1(0-1)$ & $0(0-0.2)$ & $1(0.9-1)$ & $2(1-3)$ & $35(31-39)$ & $25(18-29)$ \\
\hline$P$ value & & 0.235 & 0.071 & $0.023^{*}$ & 0.065 & $0.012^{*}$ & 0.951 & 0.900 & 0.941 & $0.047^{*}$ \\
\hline
\end{tabular}

PSQI Pittsburgh sleep quality index, SQ subjective sleep quality, SD sleep duration, $S E$ habitual sleep efficiency, $S B$ sleep disturbances, $D D$ daytime dysfunction due to disrupted sleep, NC negative coping, $P C$ positive coping

$\mathrm{n}=$ Frequency; $\%=$ Percentage, $I Q R$ Interquartile range; ${ }^{* *} P<0.01 ;{ }^{*} P<0.05$

\section{Positive and negative coping style}

The median score for negative coping style was 25.0, with an IQR from 19.0 to 30.0. The median score for positive coping style was 35.0, with an IQR from 31.0 to 39.0. Drinking and smoking were significantly associated with negative coping styles. Participants who drank had a higher level of negative coping style than non-drinkers $(P=0.031)$. Participant who smoked had a higher level of negative coping style than non-smokers $(P=0.047)$ (Table 1).

\section{Sleep quality}

The median score for the overall PSQI was 7.0 (IQR, 4.0 9.0), with $40.9 \%(200 / 489)$ of the subjects reporting poor sleep quality. The percent of participants who had domain scores $\geq 2$ were as follows: daytime dysfunction due to disrupted sleep, 56.1\% (274/489); sleep latency, 45.8\% (224/489); subjective sleep quality, 35.6\% (174/ 489); sleep duration, $13.5 \%$ (66/489); sleep disturbances, 11.9\% (58/489); habitual sleep efficiency, 6.1\% (30/489); and the use of sleep medication, $0.4 \%$ (2/489).

Compared to a sample of Chinese inland army members $(n=314)$ [32], the study participants had significantly higher scores in the SQ $(1.28$ vs $0.86, P<0.01)$, SL $(1.71$ vs 1.22 , $P<0.01)$, and DD (1.63 vs $0.78, P<0.01)$ domains and in the total PSQI score (6.76 vs $5.69, P<0.01)$ (Table 2$)$.

\section{Quality of life}

The median score for the SF-36 physical component was 83.5 (IQR, $73.0 \sim 90.5$ ), and the median score for the SF36 mental component was 74.1 (IQR, 60.4 85.1). Table 2 presents the comparisons of the HRQoL scores of our 
Table 2 Comparisons of SF-36 and PSQI scores between participants and Chinese norms

\begin{tabular}{|c|c|c|c|c|c|}
\hline Variables & & $\begin{array}{l}\text { Study group } \\
(n=489)\end{array}$ & $\begin{array}{l}\text { Chinese norms }{ }^{\mathrm{a}} \\
\text { (aged 18-44 years) } \\
(n=876)\end{array}$ & $\begin{array}{l}\text { Chinese Armed force }{ }^{b} \\
\text { (aged 17-36 years) } \\
(n=314)\end{array}$ & $P$ value \\
\hline \multirow[t]{8}{*}{ SF-36 } & $\mathrm{GH}$ & $77.2 \pm 20.8$ & $60.0 \pm 19.8$ & & $<0.01$ \\
\hline & $\mathrm{RP}$ & $82.7 \pm 32.8$ & $85.3 \pm 29.0$ & & 0.13 \\
\hline & $\mathrm{BP}$ & $70.5 \pm 19.6$ & $85.0 \pm 17.8$ & & $<0.01$ \\
\hline & PF & $92.6 \pm 14.7$ & $86.0 \pm 18.0$ & & $<0.01$ \\
\hline & $\mathrm{MH}$ & $67.8 \pm 17.6$ & $57.9 \pm 21.4$ & & $<0.01$ \\
\hline & VT & $64.7 \pm 19.1$ & $53.3 \pm 20.3$ & & $<0.01$ \\
\hline & RE & $72.8 \pm 39.7$ & $85.3 \pm 30.5$ & & $<0.01$ \\
\hline & SF & $78.4 \pm 19.4$ & $84.2 \pm 16.9$ & & $<0.01$ \\
\hline \multirow[t]{8}{*}{ PSQI } & SQ & $1.28 \pm 0.95$ & & $0.86 \pm 0.79$ & $<0.01$ \\
\hline & SL & $1.71 \pm 1.68$ & & $1.22 \pm 0.95$ & $<0.01$ \\
\hline & SD & $0.87 \pm 0.67$ & & $0.86 \pm 0.92$ & 0.86 \\
\hline & SE & $0.38 \pm 0.63$ & & $0.93 \pm 1.11$ & $<0.01$ \\
\hline & SB & $0.89 \pm 0.60$ & & $0.97 \pm 0.59$ & 0.06 \\
\hline & SM & $0.01 \pm 0.14$ & & $0.06 \pm 0.26$ & $<0.01$ \\
\hline & $\mathrm{DD}$ & $1.63 \pm 1.08$ & & $0.78 \pm 0.89$ & $<0.01$ \\
\hline & Total & $6.76 \pm 3.55$ & & $5.69 \pm 3.31$ & $<0.01$ \\
\hline
\end{tabular}

SF-36 36-item Short form health survey, $P S Q I$ Pittsburgh sleep quality index, GH general health, $R P$ role-physical, $B P$ bodily pain, $P F$ physical functioning, $M H$ mental health, $V T$ vitality, $R E$ role-emotional, $S F$ social functioning, SQ subjective sleep quality, $S L$ sleep latency, $S D$ sleep duration, $S E$ habitual sleep efficiency, $S B$ sleep disturbances, $S M$ the use of sleep medication, $D D$ daytime dysfunction due to disrupted sleep

a normative data from a sample of citizens in Hangzhou of China

${ }^{b}$ normative data from a sample of Chinese inland army

participants with the normative data. The participants of this study had statistically higher scores in the following four domains: GH (77.2 vs $60.0, P<0.01)$, PF (92.6 vs 86.0, $P<0.01), \mathrm{MH}(67.8$ vs 57.9, $P<0.01)$ and VT (64.7 vs $53.3, P<0.01)$ and showed significantly lower scores in the following three domains: $\mathrm{BP}$ (70.5 vs $85.0, P<0.01)$, RE (72.8 vs $85.3, P<0.01)$ and SF (78.4 vs $84.2, P<0.01$ ) (Table 2). The normative data were from a Chinese population in Hangzhou city and obtained by cluster sampling [33]. A total of 1688 responses were received and divided into three subgroups: a young and middle-aged group under the age of 45 years old, a middle-aged group between the age of 45 and 64 years old, and an adult group older than 65 years.

\section{Differences in sleep quality and HRQoL according to different individual characteristics}

As shown in Table 1, significant differences were found in the scores for global PSQI $(P=0.003)$ and SB $(P=0.006)$ between participants who had a habit of drinking and those who did not. Participant who smoked had a higher level of sleep disorders, including SQ $(P=0.023)$ and SE $(P=0.012)$. Participants with higher education levels had a significantly higher level of sleep disorders, including $\mathrm{SD}$ $(P<0.01), \mathrm{SB}(P<0.01)$ and DD $(P<0.01)$.

Table 3 displays the comparisons of median scores for the SF-36 domains according to different individual characteristics. The married participants had worse HRQoL regarding physical functioning $(P=0.008)$ and role limitations due to physical health $(P=0.014)$ than unmarried participants. The participants who had a habit of drinking had worse HRQoL in terms of bodily pain than those who did not drink $(P=0.032)$. The participants who were smokers had worse HRQoL in terms of vitality (energy/fatigue) than those who were nonsmokers $(P<0.05)$.

\section{Comparisons of HRQoL among good sleepers and poor sleepers}

Based on the PSQI global score, the sample was divided into two groups: good sleepers (scores $\leq 7)(n=289)$ and poor sleepers (score $\geq 8) \quad(n=200)$. The good sleepers demonstrated better HRQoL in terms of bodily pain $(P<0.01)$, vitality $(P=0.041)$ and physical functioning $(P<0.01)$ (Table 3$)$. A significantly higher physical component score (PCS) was found among good sleepers than among poor sleepers $(P<0.01)$, while no significant difference between the two groups was found regarding the mental component score (MCS) $(P=0.26)$.

\section{Associations between various variables}

There were significant moderate correlations between the PSQI and bodily pain (BP) $(r=-0.435, P<0.01)$, the PSQI and the SAS $(r=0.469, P<0.01)$, the PSQI 
Table 3 Comparisons on SF-36 subscales among different variables

\begin{tabular}{|c|c|c|c|c|c|c|c|c|c|}
\hline Variables & n (\%) & $\begin{array}{l}\text { GH } \\
\text { median(IQR) }\end{array}$ & $\mathrm{RP}$ & BP & PF & $\mathrm{MH}$ & $V T$ & RE & SF \\
\hline \multicolumn{10}{|l|}{ Marriage } \\
\hline Unmarried & 459(93.9) & $82(65-97)$ & $100(75-100)$ & $72(62-84)$ & 100(95-100) & $68(56-80)$ & $65(50-80)$ & 100(33.3-100) & $87.5(75-87.5)$ \\
\hline Married & $30(6.1)$ & $68.5(60-93.3)$ & $87.5(43.8-100)$ & $62(59.3-74)$ & $95(90-100)$ & $70(48-81)$ & $70(55-80)$ & $100(25-100)$ & $75(62.5-87.5)$ \\
\hline$P$ value & & 0.106 & $0.014^{*}$ & 0.060 & $0.008^{* *}$ & 0.887 & 0.559 & 0.980 & 0.301 \\
\hline \multicolumn{10}{|l|}{ Current Drinker } \\
\hline Yes & $36(54.0)$ & $81(65-97)$ & 100(75-100) & $62(51-73.5)$ & $95(86.3-100)$ & $68(52-84)$ & $60(51.3-75)$ & 100(66.7-100) & $75(62.5-87.5)$ \\
\hline No & $453(46.0)$ & $82(62-97)$ & 100(75-100) & $72(62-84)$ & 100(95-100) & $68(56-80)$ & $65(50-80)$ & 100(33.3-100) & $87.5(75-87.5)$ \\
\hline$P$ value & & 0.902 & 0.809 & $0.032^{*}$ & 0.082 & 0.754 & 0.385 & 0.343 & 0.343 \\
\hline \multicolumn{10}{|l|}{ Current Smoker } \\
\hline Yes & 264(54.0) & $82(65-97)$ & $100(75-100)$ & $72(62-84)$ & 100(95-100) & $68(56-80)$ & $65(50-80)$ & 100(33.3-100) & $87.5(75-87.5)$ \\
\hline No & $225(46.0)$ & $82(60-97)$ & 100(75-100) & $72(62-84)$ & 100(94.3-100) & $68(56-80)$ & 70(55-80) & 100(66.7-100) & $87.5(75-87.5)$ \\
\hline$P$ value & & 0.939 & 0.998 & 0.912 & 0.684 & 0.449 & $0.016^{*}$ & 0.521 & 0.206 \\
\hline \multicolumn{10}{|l|}{ Sleep quality } \\
\hline $\begin{array}{l}\text { Good sleeper } \\
\text { ( } \leq 7 \text { PSQI) }\end{array}$ & $289(59.1)$ & $82(65-97)$ & 100(75-100) & $72(62-100)$ & 100(95-100) & $68(56-80)$ & $70(55-80)$ & 100(33.3-100) & $87.5(75-87.5)$ \\
\hline $\begin{array}{l}\text { Poor sleeper } \\
\text { (> } 7 \text { PSQI) }\end{array}$ & $200(40.9)$ & $82(60-92)$ & 100(75-100) & $62(51-72)$ & $95(90-100)$ & $68(56-80)$ & 65(50-78.8) & 100(41.7-100) & $78.7(62.5-87.5)$ \\
\hline$P$ value & & 0.100 & 0.477 & $0.000^{* *}$ & $0.000^{* *}$ & 0.550 & $0.041^{*}$ & 0.746 & 0.114 \\
\hline \multicolumn{10}{|l|}{ Anxiety } \\
\hline $\begin{array}{l}\text { Without } \\
\text { ( } \leq 50 \text { SAS) }\end{array}$ & $426(84.9)$ & $82(62-97)$ & 100(75-100) & $72(62-84)$ & 100(95-100) & $68(56-80)$ & $65(50-80)$ & 100(33.3-100) & $87.5(75-87.5)$ \\
\hline $\begin{array}{l}\text { With } \\
\text { (> 50 SAS) }\end{array}$ & $63(15.1)$ & $77(60-97)$ & $100(50-100)$ & $62(50-72)$ & $95(80-100)$ & $68(52-84)$ & $70(50-80)$ & 100(66.7-100) & $87.5(62.5-87.5)$ \\
\hline$P$ value & & 0.546 & 0.098 & $0.000^{* *}$ & $0.010^{*}$ & 0.912 & 0.782 & 0.952 & 0.567 \\
\hline
\end{tabular}

SF-36 36-item Short form health survey, $P S Q I$ Pittsburgh sleep quality index, SAS Self-rating anxiety scale, GH general health, $R P$ role-physical, $B P$ bodily pain, $P F$ physical functioning, $M H$ mental health, $V T$ vitality, $R E$ role-emotional, $S F$ social functioning

$\mathrm{n}=$ Frequency; $\%=$ Percentage; ${ }^{* *} \mathrm{P}<0.01 ;{ }^{*} \mathrm{P}<0.05$

and NC $(r=0.382, P<0.01)$, BP and the SAS $(r=0.423$, $P<0.01)$, and BP and NC $(r=0.304, P<0.01)$ (Table 4).

\section{Sleep quality independently affects the PCS and the SAS} As shown by the multiple regression results in Table 5, the PCS was affected by anxiety symptoms, marital status, educational background, and global PSQI score $(F=17.06$, $P<0.001, R^{2}=0.117$ ), and poor sleep quality was an independent predictor of low PCS. Anxiety was significantly affected by coping strategies, global PSQI score and education level, and poor sleep quality was also a significant predictor for developing anxiety symptoms $(F=70.49$, $P<0.001, \mathrm{R}^{2}=0.364$ ).

\section{Conceptual model of sleep quality and HRQoL}

A conceptual model of how sleep quality impacts HRQoL among military personnel was developed according to the Wilson and Cleary model [34] for

Table 4 Correlation coefficients between various variables

\begin{tabular}{|c|c|c|c|c|c|c|c|c|}
\hline Variables & Role-physical & Mental health & Vitality & Role-emotional & Social functioning & Negative coping & Anxiety & Sleep quality \\
\hline General health & $0.301^{* *}$ & $0.352^{* *}$ & $0.328^{* *}$ & $0.295^{* *}$ & $0.402^{* *}$ & $-0.105^{* *}$ & - & - \\
\hline Role-physical & - & $0.141^{* *}$ & $0.208^{* *}$ & $0.431^{* *}$ & $0.344^{* *}$ & - & - & - \\
\hline Bodily pain & - & - & - & - & $0.117^{* *}$ & $-0.304^{* *}$ & $-0.423^{* *}$ & $-0.435^{* *}$ \\
\hline Mental health & - & - & - & - & $0.470^{* *}$ & - & - & - \\
\hline Vitality & - & $0.636^{* *}$ & - & - & $0.492^{* *}$ & - & - & - \\
\hline Role-emotional & - & $0.356^{* *}$ & $0.328^{* *}$ & - & $0.430^{* *}$ & - & - & - \\
\hline Positive coping & - & - & - & - & - & $-0.302^{* *}$ & $-0.417^{* *}$ & - \\
\hline Negative coping & - & - & - & - & - & - & $0.546^{* *}$ & $-0.382^{* *}$ \\
\hline Anxiety & - & - & - & - & - & - & - & $-0.469^{* *}$ \\
\hline
\end{tabular}

Only significant correlations were presented. ${ }^{* *} P<0.01$; The correlation coefficient $>0.3$ were presented in bold 
Table 5 Multiple linear regressions of predictors to HRQoL and Anxiety

\begin{tabular}{|c|c|c|c|c|}
\hline Variables & $\mathrm{B} \pm \mathrm{SE}$ & Beta $(\beta)$ & $t$ & $P$ value \\
\hline \multicolumn{5}{|c|}{ PCS (adjusted R ${ }^{2}=0.117$ ) } \\
\hline Constant & $109.408 \pm 3.89$ & & 28.129 & $<0.001$ \\
\hline Anxiety & $-0.307 \pm 0.67$ & -0.213 & -4.559 & $<0.001$ \\
\hline Marriage & $-7.310 \pm 2.36$ & -0.134 & -3.093 & 0.002 \\
\hline PSQI & $-0.505 \pm 0.17$ & -0.137 & -2.927 & 0.004 \\
\hline Education & $-1.865 \pm 0.71$ & -0.115 & -2.628 & 0.009 \\
\hline \multicolumn{5}{|c|}{ Anxiety (adjusted $R^{2}=0.364$ ) } \\
\hline Constant & $42.581 \pm 2.59$ & & 16.470 & $<0.001$ \\
\hline NC & $0.421 \pm 0.05$ & 0.359 & 9.039 & $<0.001$ \\
\hline PC & $-0.369 \pm 0.05$ & -0.256 & -6.891 & $<0.001$ \\
\hline PSQI & $0.579 \pm 0.10$ & 0.226 & 5.757 & $<0.001$ \\
\hline Education & $-1.020 \pm 0.41$ & -0.091 & -2.502 & 0.013 \\
\hline
\end{tabular}

PSQI Pittsburgh sleep quality index, PCS physical component summary, NC negative coping, $P C$ positive coping

HRQoL. As shown in the conceptual model (Fig. 1), individual characteristics (e.g., smoking, drinking, education, marital status, coping strategies, anxiety) and environmental characteristics (extreme cold) are factors impairing soldiers' sleep quality. The symptoms of impaired sleep quality included increased sleep latency, decreased sleep efficiency and daytime dysfunction due to insufficient sleep. These symptoms had a wideranging detrimental impact on physical and mental functioning, which consequently contributed to the decline in HRQoL.

\section{Discussion}

The present study demonstrated poorer HRQoL in the military population regarding pain, role limitations and social functioning than in the normative data from the general population but better HRQoL in terms of general health, physical functioning, emotional well-being and vitality. Sleep quality and anxiety are contributing factors that influence physical-related quality of life. Moreover, the poor sleepers exhibited more impaired HRQoL in relation to physical complaints than the good sleepers, suggesting that sleep had a greater impact on the physical health component than on the mental health component. In terms of recommendations for improving HRQoL in military personnel, health interventions should be given not only to reduce emotional disorders such as anxiety but also to control physical symptoms including pain and sleep disorders and to improve social participation and communication.

The results may be challenged by the traditional beliefs that military personnel are at high risk of psychiatric problems because they are facing more stressful military tasks and a more austere environment. However, evidence is emerging that military troops tend to have better psychological resilience than civilians and volunteers. Military and police officers are relatively less likely to suffer from PTSD than civilians [35]. One reason for this phenomenon, we assumed, is that individuals who choose to take on military roles tend to have solid beliefs and spirits devoted to the nation and people, and they tend to feel great responsibility for national defence, so they present high resilience in the face of difficulties [36]. Another reason relies on the increasing awareness and implementation of programmes on stress management and resilience to military personnel due to their high risks of mental disorders. This training helps them be better prepared to handle psychological threats than civilians who seldom have the opportunities to be trained [37-39]. Moreover, military officers are frequently exposed to complicated situations during daily training so they are familiar with stress management strategies through repetitive practice.

This study contributed to previous findings by showing that sleep disorder was a prevalent problem among troops located in austere environments, especially in terms of poor subjective sleep quality, prolonged sleep latency and daytime impairment. One study among island garrisons revealed an overall PSQI score of $7.58 \pm$ 2.96 , with $45.7 \%$ of the subjects reporting poor sleep quality [40]. Sleep latency, daytime dysfunction, sleep disturbances, and sleep efficiency were reported as prominent problems among the island troops. Another study among Chinese inland armed forces disclosed an overall PSQI score of $5.69 \pm 3.28$, and one in four had poor sleep quality. The primary problems were sleep latency, sleep efficiency, vitality and daytime dysfunction. Kong and associates found a global PSQI score of 8.14 \pm 3.79 among young soldiers stationed on the Tibetan Plateau [11]. Several reasons for sleep problems in austere environments include noise, extreme temperatures, frequent shift work, and crowded sleeping areas [41]. Moreover, servicemen undergoing multiple combat deployments were more likely to be exposed to the conditions that disrupted sleep than servicemen undergoing fewer deployments. A survey of service members and veterans of Operation Enduring Freedom and Operation Iraqi Freedom showed clinically significant poor sleep quality, with a mean global PSQI score of $10.36 \pm 4.55$. The mean score resembled normative data among poor sleepers or those with sleep disorders. Other than objective reasons, the subjective reasons contributing to sleep difficulties were reported as pain, hypervigilance, hyperarousal, nightmares, and an avoidance of sleep due to a fear of nightmares [42].

It was also demonstrated that pain served as a negative factor for sleep quality and anxiety symptoms in this study. Body pain was found to reduce sleep quality, 


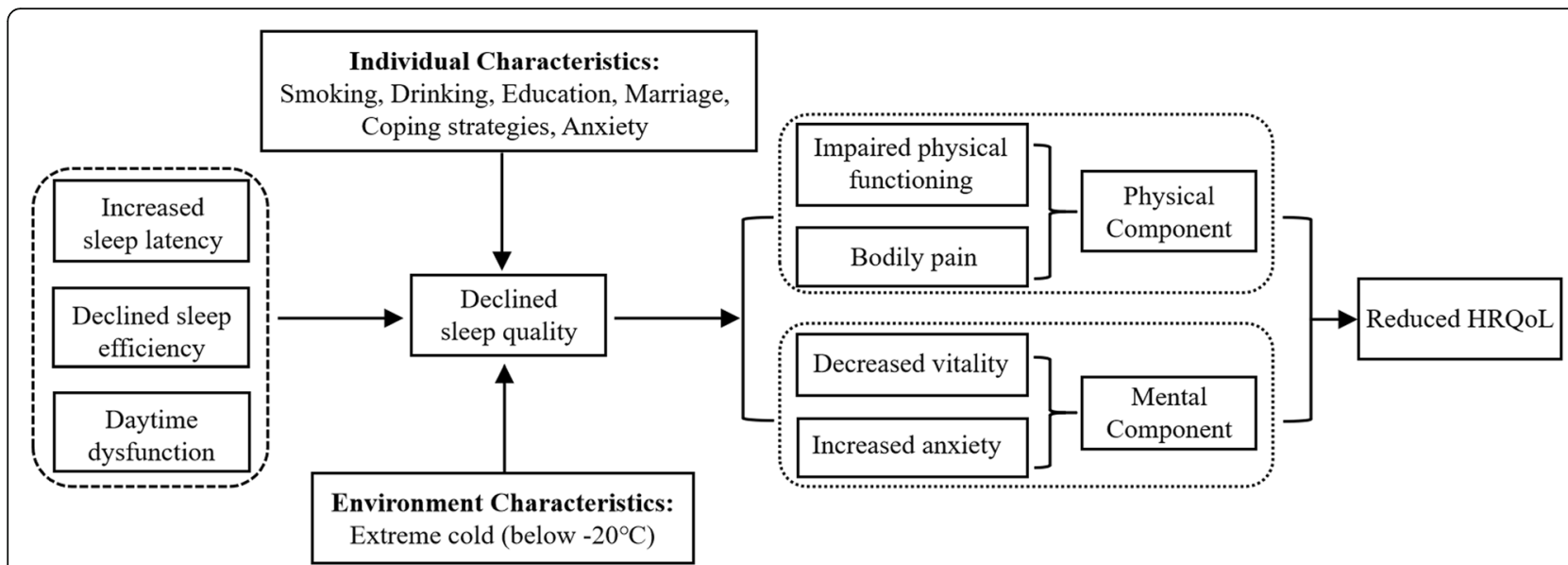

Fig. 1 Conceptual model of impaired sleep quality and its impacts on decreased HRQOL

result in negative coping strategies, increase anxiety symptoms, and eventually decrease HRQoL; in turn, poor sleep quality could also enhance the experience of pain or contribute to a lower pain threshold [43]. However, the problems of bodily pain and its negative effects were underestimated and ignored in the Chinese military. Injuries and pain occurred frequently when highintensity physical training was required, though inappropriate training methods or procedures were not used. However, the number of those who approached health professionals was only a small portion of those who truly suffered from chronic pain. A majority of servicemen chose to suffer pain in silence for fear of the stigma associated with reporting pain. In Chinese military culture, a soldier is often regarded as symbol of power, strength and reliability; complaining about pain would involve being stigmatized as being weak, incapable or less fit for promotion [44]. As a result, instead of complaining about pain, soldiers may address their sleep complaints because sleep problems are regarded as medical problems in nature. Therefore, the evaluation of pain is important and encouraged when treating soldiers who complain about sleep difficulties. Additionally, adding pain management information into regular health education for the military could be a normalizing intervention to reduce the discrimination related to medical visits due to pain.

This study contributed to the current evidence that negative coping strategies and poor sleep quality could result in anxiety symptoms, with the supporting results including the positive correlation between the $\mathrm{NC}$ and SAS scores, between the NC and PSQI and between the PSQI and the SAS (Table 4) and the results of the regression analysis (Table 5). The participants with insufficient sleep were more likely to adopt negative coping strategies such as "restraint or suppression" or "denial", which further aggravated anxious symptoms.
Several limitations of this study should be noted. First, the sample size was not large enough to include more female soldiers and more military personnel from different ranks. This may reduce the positive outcomes when examining the impacts of demographic variables on sleep quality and HRQoL. Another limitation was the data being collected during a relative peacetime, which limits the results' application to military personnel on deployment or in combat. Moreover, the ability to examine the relationships between cause and effect for all factors was limited due to the cross-sectional study design.

\section{Conclusions}

This study examined the current status of sleep quality, anxiety and HRQoL in a Chinese military population from an austere environment. In summary, sleep disorders were a prevalent but underestimated problem in the military, which negatively influenced the overall HRQoL, especially in terms of physical and social functioning. The evaluation of pain and education on pain management were recommended because body pain and its negative impacts on sleep quality, coping strategies, anxious emotions and HRQoL have been found.

\section{Abbreviations}

PTSD: Post-traumatic stress disorder; HRQoL: Health-related quality of life; PSQI: Pittsburgh Sleep Quality Index; SAS: Self-rating Anxiety Scale; MOS-SF36: Medical Outcomes Study Short Form-36; SQ: Subjective sleep quality; SB: Sleep disturbances; SM: The use of sleep medication; SE: Habitual sleep efficiency; SL: Sleep latency; SD: Sleep duration; DD: Daytime dysfunction due to disrupted sleep; TCSQ: Trait Coping Style Questionnaire; PCS: Physical Component Summary; MCS: Mental Component Summary; GH: General health; RP: Role limitations due to physical health (role-physical); BP: Bodily pain; PF: Physical functioning; MH: Mental health; VT: Vitality; SF: Social functioning; RE: Role limitations due to emotional problems; NC: Negative coping; PC: Positive coping

Acknowledgments

Sincerely appreciate Mr. Dingguo Cheng for help with recruiting participants. 


\section{Authors' contributions}

AL and ZW designed the study. QS, ZW, and BC acquired the data. ZW, BC, WL and FX analyzed the data. QS, ZW, BC and AL interpreted the data and developed the conceptual model. ZW and QS drafted the manuscript. AL revised the manuscript. The authors read and approved the final manuscript.

\section{Funding}

This study was funded by Innovation Research Grants of Army Medical University (4103010530). The sponsor or funding organization had no role in the design or conduct of this research, data analysis or manuscript preparation.

\section{Availability of data and materials}

The data used and/or analyzed during the current study are available from the corresponding author on reasonable request.

\section{Ethics approval and consent to participate}

Ethical approval was obtained from the human ethics committee of the Army Medical University.

\section{Consent for publication}

Not applicable.

\section{Competing interests}

No authors have any financial interest to disclose.

Received: 19 February 2020 Accepted: 22 June 2020

Published online: 13 July 2020

\section{References}

1. Bramoweth AD, Germain A. Deployment-related insomnia in military personnel and veterans. Curr Psychiatry Rep. 2013;15:401

2. Yarnell A, Deuster P. Sleep as a strategy for optimizing performance. J Spec Oper Med. 2016;16:81-5.

3. Mysliwiec V, Walter RJ, Collen J, Wesensten N. Military sleep management: an operational imperative. US Army Med Dep J. 2016;(2-16):128-34.

4. Boyko EJ, Seelig AD, Jacobson IG, Hooper TI, Smith B, Smith TC, CrumCianflone NF, Millennium Cohort Study T. Sleep characteristics, mental health, and diabetes risk: a prospective study of U.S. military service members in the millennium cohort study. Diabetes Care. 2013;36:3154-61.

5. Gehrman P, Seelig AD, Jacobson IG, Boyko EJ, Hooper TI, Gackstetter GD, Ulmer CS, Smith TC, Team MCS. Predeployment sleep duration and insomnia symptoms as risk factors for new-onset mental health disorders following military deployment. Sleep. 2013:36:1009-18.

6. Ribeiro JD, Pease JL, Gutierrez PM, Silva C, Bernert RA, Rudd MD, Joiner TE. Sleep problems outperform depression and hopelessness as cross-sectional and longitudinal predictors of suicidal ideation and behavior in young adults in the military. J Affect Disord. 2012:136:743-50.

7. van Liempt S, van Zuiden M, Westenberg H, Super A, Vermetten E. Impact of impaired sleep on the development of Ptsd symptoms in combat veterans: a prospective longitudinal cohort study. Depress Anxiety. 2013;30: 469-74

8. Olsen OK, Pallesen S, Torsheim T, Espevik R. The effect of sleep deprivation on leadership behaviour in military officers: an experimental study. J Sleep Res. 2016;25:683-9.

9. Taylor MK, Hilton SM, Campbell JS, Beckerley SE, Shobe KK, Drummond SPA, Team BHNA. Prevalence and mental health correlates of sleep disruption among military members serving in a combat zone. Mil Med. 2014;179:744-51.

10. Van Dongen HP, Maislin G, Mullington JM, Dinges DF. The cumulative cost of additional wakefulness: dose-response effects on neurobehavioral functions and sleep physiology from chronic sleep restriction and total sleep deprivation. Sleep. 2003;26:117-26.

11. Kong FY, Li Q, Liu SX. Poor sleep quality predicts decreased cognitive function independently of chronic mountain sickness score in young soldiers with polycythemia stationed in Tibet. High Alt Med Biol. 2011;12: 237-42.

12. Zeng WF, Yan WJ, Song W, Su T. Investigation of sleep quality and life quality of soldiers in a navy warship troop. Acad J Second Mil Univ. 2018;39: 211-5.
13. Wang K, Qin XY, Feng YC, Li JY, Xiao L, He JW, Su T. Survey on sleep quality and life quality of navy servicemen stationed on an island. Acad J Second Mil Univ. 2020;41:237-42.

14. Buysse DJ, Reynolds CF 3rd, Monk TH, Berman SR, Kupfer DJ. The Pittsburgh sleep quality index: a new instrument for psychiatric practice and research. Psychiatry Res. 1989;28:193-213.

15. Zung WW. A rating instrument for anxiety disorders. Psychosomatics. 1971; 12:371-9.

16. Jiang Q. The Chinese trait coping style questionnaire. Rating Scales Ment Health 2nd ed Chin J Ment Health. 1999:120-2.

17. Li L, Wang H, Shen Y. Development and psychometric tests of a Chinese version of the SF-36 health survey scales. Zhonghua Yu Fang Yi Xue Za Zhi. 2002:36:109-13.

18. Henry M, Wolf PS, Ross IL, Thomas KG. Poor quality of life, depressed mood, and memory impairment may be mediated by sleep disruption in patients with Addison's disease. Physiol Behav. 2015;151:379-85.

19. Tsai PS, Wang SY, Wang MY, Su CT, Yang TT, Huang CJ, Fang SC. Psychometric evaluation of the Chinese version of the Pittsburgh sleep quality index (CPSQI) in primary insomnia and control subjects. Qual Life Res. 2005;14:1943-52.

20. Ho RT, Fong TC. Factor structure of the Chinese version of the Pittsburgh sleep quality index in breast cancer patients. Sleep Med. 2014;15:565-9.

21. Liu X, Tang M, Hu L. Reliability and validity of the Pittsburgh sleep quality index. Chin J Psychiatry. 1996;29:103-7.

22. Jegede RO. Psychometric attributes of the self-rating anxiety scale. Psychol Rep. 1977;40:303-6.

23. Dunstan DA, Scott N, Todd AK. Screening for anxiety and depression: reassessing the utility of the Zung scales. BMC Psychiatry. 2017:17:329.

24. Liu XC, Tang MQ, Dai XG, Chen K, Dai ZS. Factor analysis of self-rating anxiety scale. Chin J Nervous Mental Dis. 1995;21:359-60.

25. Dunstan DA, Scott N. Norms for Zung's Self-rating Anxiety Scale. BMC Psychiatry. 2020;20(1):90.

26. Zung WW. The measurement of affects: depression and anxiety. Mod Probl Pharmacopsychiatry. 1974;7:170-88.

27. Liu XC, Tein JY, Zhao ZT. Coping strategies and behavioral/emotional problems among Chinese adolescents. Psychiatry Res. 2004;126:275-85.

28. Ding YQ, Yang YJ, Yang XX, Zhang TH, Qiu XH, He X, Wang WB, Wang L, Sui $H$. The mediating role of coping style in the relationship between psychological capital and burnout among Chinese nurses. PLoS One. 2015; 10:e0122128.

29. Ware JE, Gandek B, Aaronson NK, Acquadro C, Alonso J, Apolone G, Bech P, Brazier J, Bullinger M, Fukuhara S, et al. The Sf-36 health survey development and use in mental-Health Research and the lqola project. Int $J$ Ment Health. 1994;23:49-73.

30. Li L, Wang HM, Shen Y. Chinese SF-36 health survey: translation, cultural adaptation, validation, and normalisation. J Epidemiol Community Health. 2003:57:259-63.

31. Ratner B. The correlation coefficient: Definition [http://www.dmstat1.com/ res/TheCorrelationCoefficientDefined.html]. Accessed 8 July.

32. Shan $L$, Junyang $X$, Shuai $Z$, Juntao $Y$. research on the relationship between sleep quality and defense styles of army soldiers. Mil Med J S China. 2016: 30:725-8.

33. Shan W, Wenjie F, Wanqi $Y$, Jian L, Dange $X$, Hongyan C, Ying $X$, Xiuyang L Analysis on reliability and validity of SF-36 scale in urban residents. Chin J Epidemiol. 2016:37:344-7.

34. Ferrans CE, Zerwic JJ, Wilbur JE, Larson JL. Conceptual model of healthrelated quality of life. J Nurs Scholarsh. 2005:37:336-42.

35. Mao XR, Fung OWM, Hu XY, Loke AY. Psychological impacts of disaster on rescue workers: a review of the literature. Int J Disaster Risk Reduction. 2018; 27:602-17.

36. Marshall RE, Milligan-Saville JS, Mitchell PB, Bryant RA, Harvey SB. A systematic review of the usefulness of pre-employment and pre-duty screening in predicting mental health outcomes amongst emergency workers. Psychiatry Res. 2017:253:129-37.

37. McCaslin SE, Herbst ED, Armitage NH, Allen I, Neylan T, Becket-Davenport C, Choucroun G, Best S, Inslicht SS. Deployment anxiety reduction training: a pilot study of acceptability and feasibility in current or recent active duty service members. Mil Med. 2018;183:371-8.

38. Meredith LS, Sherbourne CD, Gaillot SJ, Hansell L, Ritschard HV, Parker AM, Wrenn G. Promoting psychological resilience in the US military. Rand Health Q. 2011;1:2. 
39. Delahaij R, Soeters J. Stress training and the new military environment. TNO Defence security and safety soesterberg (NETHERLANDS); 2006.

40. Xin J, Nie J. A survey of dyssomnias and the influential factors involved among soldiers stationed on the island. J Mil Med Res. 2012;37:657-8.

41. Peterson AL, Goodie JL, Satterfield WA, Brim WL. Sleep disturbance during military deployment. Mil Med. 2008;173:230-5.

42. Plumb TR, Peachey JT, Zelman DC. Sleep disturbance is common among Servicemembers and veterans of operations enduring freedom and Iraqi freedom. Psychol Serv. 2014;11:209-19.

43. Kim SH, Kim H, Kim S, Paek S, Koh JH, Lee J, Cho YW, Park SH. Sleep quality independently affects health-related quality of life and cognitive function in Korean female patients with rheumatoid arthritis: a case-control study. J Korean Med Sci. 2018;33:e216.

44. Schoneboom BA, Perry SM, Barnhill WK, Giordano NA, Wiltse Nicely KL, Polomano RC. Answering the call to address chronic pain in military service members and veterans: Progress in improving pain care and restoring health. Nurs Outlook. 2016;64:459-84.

\section{Publisher's Note}

Springer Nature remains neutral with regard to jurisdictional claims in published maps and institutional affiliations.

Ready to submit your research? Choose BMC and benefit from:

- fast, convenient online submission

- thorough peer review by experienced researchers in your field

- rapid publication on acceptance

- support for research data, including large and complex data types

- gold Open Access which fosters wider collaboration and increased citations

- maximum visibility for your research: over $100 \mathrm{M}$ website views per year

At BMC, research is always in progress.

Learn more biomedcentral.com/submissions 